\title{
BANCO DE DADOS
}

SOCIOLINGUÍSTICOS DA

FRONTEIRA E DA CAMPANHA SUL-

RIO-GRANDENSE - BDS PAMPA UM PERCURSO HISTÓRICO

\author{
DATABASE THAT STORES SOCIOLINGUISTIC DATA IN THE \\ EXTREME SOUTH OF RIO GRANDE DO SUL STATE - BDS \\ PAMPA - A HISTORICAL ROUTE
}

\author{
Paulo Ricardo Silveira BORGES ${ }^{1}$ \\ Luciene Bassols BRISOLARA²
}

\begin{abstract}
Resumo: O Banco de Dados Sociolinguísticos da Fronteira e da Campanha Sul-Rio-Grandense (BDS PAMPA) foi desenvolvido, em 1998, a partir da parceria entre a Universidade Católica de Pelotas (UCPel) e a Universidade Federal de Pelotas (UFPel), com a finalidade de constituir um banco de dados sociolinguísticos do português falado na fronteira e na campanha sul-rio-grandense. A metodologia de formação do BDS PAMPA segue os preceitos da Sociolinguística Variacionista (LABOV, 1972, 1994). Para cada informante consta ficha social, gravação de entrevista, transcrição ortográfica dos dados linguísticos, digitalização das fichas sociais, compactação das gravações e conversão para CDROM. O banco de dados do BDS PAMPA tem como objetivos mostrar a importância da utilização de banco de dados sociolinguísticos para a descrição do português brasileiro e possibilitar que diversas pesquisas e trabalhos de cunho sociolinguístico sejam realizados. Além disso, neste ano de 2020, com a participação da Universidade Federal do Rio Grande (FURG), buscamos uma parceria interinstitucional com o objetivo de realizar recontato com informantes do Banco de Dados da década de 90, realizar novas coletas de dados nas mesmas localidades, com novos informantes, bem como elaborar uma nova ficha social, a fim de registrar outros aspectos sociolinguísticos não contemplados na ficha atual.
\end{abstract}

Palavras-chave: Sociolinguística. Banco de dados. Fronteira. Campanha. BDS PAMPA.

\begin{abstract}
The Project BDS Pampa, a database that stores sociolinguistic data in the extreme south of Rio Grande do Sul state, Brazil, was developed in 1998, from the partnership between Catholic University of Pelotas (UCPel) and Federal University of Pelotas (UFPel), with the purpose of establishing a sociolinguistic database of Portuguese spoken at the border and in the South-Rio Grande campaign. The methodology of BDS PAMPA training follows the precepts of Variationist Sociolinguistics (LABOV, 1972, 1994). For each informant there is a social record, interview recording, orthographic transcription of linguistic data, digitization of social cards, compression of recordings and conversion to CD-ROM. The BDS PAMPA database aims to show the importance of using a sociolinguistic database to describe Brazilian Portuguese and to enable various research and sociolinguistic work to be carried out. Furthermore, in 2020, with the participation of Federal University of Rio Grande (FURG), an interinstitutional partnership is sought with the objective of reconnecting with informants from the database from the 1990s, to carry out new data collections in the same localities, with new informants, as well as to prepare a new social record in order to register other sociolinguistic aspects not included in the current record.
\end{abstract}

Keywords: Sociolinguistics. Database. Border. Campanha region. BDS PAMPA. 1 Universidade Federal de Pelotas (UFPel), Pelotas, Rio Grande do Sul, Brasil;
paulorsborges@gmail.com; http://orcid.org/0000-0003-2660-8711

2 Universidade Federal do Rio Grande (FURG), Rio Grande, Rio Grande do Sul, Brasil; lucienebrisolara@furg.br; https://orcid.org/0000-0001-7248-6765 
- Banco de dados sociolinguísticos da fronteira e da campanha sul-rio-grandense - BDS Pampa um percurso histórico

\section{Introdução}

O Banco de Dados Sociolinguísticos da Fronteira e da Campanha Sul-RioGrandense (BDS PAMPA) foi desenvolvido a partir do primeiro semestre de 1998, parceria da Universidade Católica de Pelotas (UCPel) e da Universidade Federal de Pelotas (UFPel), tendo como finalidade a coleta de dados sociolinguísticos do português falado na fronteira e na campanha Sul-Rio-Grandense. Os professores da UCPel, Jorge Walter da Rocha Espiga, Paulino Vandresen e Carmen Lúcia Barreto Matzenauer, e da UFPel, Paulo Ricardo Silveira Borges e Luís Isaías Centeno do Amaral, foram os responsáveis pela constituição do BDS PAMPA. O banco de dados foi criado com o objetivo de descrever o português do Brasil, seja no sentido diatópico ou diastrático, e de disponibilizar amostras de fala a pesquisadores interessados nas mais variadas áreas de análise sociolinguística (fonologia, morfologia, sintaxe, semântica, etc.).

Para a composição do BDS PAMPA, as amostras foram constituídas de entrevistas com $24^{3}$ indivíduos em cada cidade, sendo 12 do sexo feminino e 12 do sexo masculino. Os indivíduos foram divididos em cinco faixas etárias (16 a 25, 26 a 37, 38 a 49, 50 a 64 e mais de 64 anos) e em dois graus de escolaridades (escolaridade 1: informantes analfabetos ou que tivessem estudado, no máximo, até a quinta série $\mathrm{e}^{4}$; escolaridade 2: a partir do primeiro ano do segundo grau, sem limite). Todos os sujeitos-informantes, que tiveram seus dados de fala coletados, preencheram uma ficha de cadastramento, na qual foram armazenadas informações sociolinguísticas, como idade, escolaridade, cidade de nascimento do sujeito investigado e dos pais, profissão, local de moradia, etc. Após essa etapa, os indivíduos eram entrevistados entre 30 e 60 minutos. As entrevistas, constituídas de narrativas de experiências pessoais, possibilitaram que os entrevistadores fizessem perguntas sobre o dia a dia dos entrevistados, bem como abordavam temas relacionados à cidade, aos costumes, aos projetos de vida, à família, aos amigos, ao trabalho, etc. A metodologia de coleta de dados seguiu o modelo de narrativa proposto por Labov $(1972,1994)$.

O banco de dados incluiu cidades brasileiras localizadas a até $200 \mathrm{~km}$ da linha da fronteira sul-rio-grandense com o Uruguai e com a Argentina, a saber: Litoral (Chuí, Santa Vitória do Palmar, Rio Grande, Pelotas, Tavares, Jaguarão e Arroio Grande), Serra do Sudeste (Piratini, Encruzilhada do Sul, Aceguá e Bagé), Pampa (Santana do Livramento,

$3 \mathrm{Na}$ cidade de Pelotas, foram entrevistados 48 sujeitos, considerando o tamanho da população.

4 Os termos "série" e "segundo grau" eram usados na época da formação do BDS PAMPA para designar o que hoje é intitulado "ano" e "ensino médio". 
Rosário do Sul, São Vicente do Sul, Quaraí, Alegrete, São Francisco de Assis, Barra do Quaraí, Uruguaiana, Itaqui e São Borja). Muitas dessas comunidades também são denominadas de "cidades fronteiriças", por estarem na linha divisória de fronteira do Brasil com o Uruguai e com a Argentina.

Para os objetivos aqui propostos, de mostrar a importância da utilização de banco de dados sociolinguísticos para a descrição do português brasileiro, trazer informações sobre a relevância do trabalho desenvolvido a partir do BDS PAMPA e projetar uma nova etapa histórica de entrevistas e recontatos com os informantes pesquisados, este trabalho estrutura-se em seções que trazem o objeto de estudo do BDS PAMPA, a metodologia para a constituição do banco de dados, a catalogação da ficha sociolinguística, entrevistas, digitação e conferência dos dados linguísticos, a especificação de trabalhos com fontes oriundas do BDS Pampa e o BDS PAMPA 20 anos depois.

\section{Objeto de estudo do BDS PAMPA}

O BDS PAMPA teve como objeto de estudo o conjunto de variedades dialetais do português sul-rio-grandense faladas na região da campanha e de fronteira, definida esta como uma faixa de território brasileiro de aproximadamente $200 \mathrm{Km}$ de largura acompanhando, no sentido longitudinal, o contorno da linha demarcatória de limites do Brasil com o Uruguai e com a Argentina. A tais variedades denominamos, genericamente, Português da Fronteira.

Entre seus objetivos destaca-se o de permitir o melhor conhecimento da realidade sociolinguística da região de fronteira do Rio Grande do Sul, a partir da consolidação de um banco de dados interinstitucional, para acesso de pesquisadores e acadêmicos da UCPel, da UFPel e de outras instituições interessadas no tema. Acrescentam-se a isso outros objetivos que também merecem destaque, levando-se em conta o momento histórico de sua criação e a necessidade de se compor Bancos de Dados fidedignos que descrevessem de forma metodológica e científica a realidade do Português do Brasil falado em zonas urbanas representativas de determinadas realidades geográficas do Brasil.

Entre os outros objetivos que nortearam o trabalho, destacam-se os seguintes: (i) consolidar um banco de dados, complementar ao VARSUL, de caráter interinstitucional, para estudos sociolinguísticos de comunidades de fala da região da fronteira; (ii) subsidiar pesquisas variacionistas e não-variacionistas de variedades dialetais pertencentes ao contínuo gaúcho; (iii) subsidiar pesquisas interdisciplinares, tendo como objeto de estudo não apenas a linguagem, mas também o conjunto de dados socioeconômicos dos informantes; (iv) subsidiar trabalhos de mapeamento dialetológico dos contínuos, 
- Banco de dados sociolinguísticos da fronteira e da campanha sul-rio-grandense - BDS Pampa um percurso histórico

delimitando linhas isoglóssicas e regiões de contato na fronteira; (v) aferir a influência do espanhol no sistema gramatical do português; (vi) aferir a influência do pomerano (e, eventualmente, de outras línguas) no sistema gramatical do português; (vii) estudaraspectos inerentes ao fenômeno de bilinguismo; (viii) estudar aspectos inerentes à formação de interlínguas ou dialetos de contato; (ix) estudar aspectos relativos à estandardização do PB, à luz da heterogeneidade dialetal, do contato e da dicotomia inovação-conservação; (x) subsidiar propostas de metodologias de alfabetização e de ensino de português em face da heterogeneidade e dos fenômenos inerentes ao contato; (xi) subsidiar técnicas e estratégias para a aquisição de língua espanhola como L2, a partir da observação do contato entre o português e o espanhol e da influência interlinguística de um sistema gramatical sobre o outro; (xii) atualizar a produção científica sociolinguística, no que se refere a estudos que considerem como fatores ou grupos de fatores da variação aspectos inerentes ao contato do português com outras línguas.

Observa-se, portanto, que o BDS PAMPA nasceu a partir da necessidade de investigação e análise de diferentes fenômenos linguísticos próprios ao português brasileiro ( $\mathrm{PB}$ ) e, em especial, ao português brasileiro-gaúcho, com as suas diferentes e diversificadas realidades em função da sua constituição sociolinguística-histórica-cultural, intrinsecamente relacionada à formação histórica do Rio Grande do Sul e da Fronteira Sul do Brasil.

\section{Metodologia para a constituição do Banco de Dados: um importante desafio a ser enfrentado}

O BDS PAMPA é um corpus de fala constituído de áudio e transcrição, a partir da tipologia da Linguística de Corpus que leva em conta critérios de validação estatística e social devidamente controlados. Além disso, o armazenamento dos dados e sua futura disponibilidade para pesquisa também mereceu atenção especial quando da elaboração do banco de dados. Como afirma Raso (2016, p. 205), um corpus é um conjunto de dados reais "planejado e coletado de modo que possa representar de maneira balanceada uma determinada porção de mundo". Um banco de dados sociolinguístico necessita representar a fala não apenas de uma comunidade de fala, mas dos indivíduos que compõem essa comunidade. Finatto (2018, p. 437) enfatiza que "a Linguística de Corpus, pelo menos no âmbito brasileiro, tornou-se um interessante ponto de encontro para diferentes estudos, independentemente de filiações teóricas ou áreas de formação dos pesquisadores envolvidos". 
A metodologia do BDS PAMPA buscou contemplar a tipologia da Linguística de Corpus para dados de fala, uma vez que a coleta de dados foi realizada por etapas, levando-se em conta planejamento metodológico que contemplasse as especificidades administrativas das Instituições envolvidas e os projetos dos pesquisadores. Buscou-se, a partir da sua constituição, abranger o maior número possível de municípios, pensandose na amplitude de pesquisas e análises futuras de diferentes aspectos linguísticos que poderiam merecer a atenção de pesquisadores da área da linguística e de outras áreas afins. E foi justamente isso que ocorreu, e ainda ocorre, justamente pela dimensão do banco de dados e pela diversidade de realidades linguísticas encontradas nas entrevistas, atendendo aos diferentes campos de saberes que compõem os estudos linguísticos nas suas múltiplas possibilidades de análises e interfaces.

Para tanto, dividiu-se os municípios em regiões de abrangência e diferentes fases para a realização das coletas de dados, conforme o Quadro 1 a seguir: 
- Banco de dados sociolinguísticos da fronteira e da campanha sul-rio-grandense - BDS Pampa um percurso histórico

Quadro 1. Mapa da Região alvo do BDS PAMPA

\begin{tabular}{|c|c|c|c|}
\hline \multirow[t]{8}{*}{ Região $1^{5}$} & \multicolumn{3}{|l|}{ Litoral: } \\
\hline & \multirow[t]{2}{*}{ Fase 1: } & a) & Chuí; \\
\hline & & b) & Santa Vitória do Palmar; \\
\hline & \multirow[t]{3}{*}{ Fase 2: } & c) & Rio Grande; \\
\hline & & d) & Pelotas; \\
\hline & & e) & Tavares; \\
\hline & \multirow[t]{2}{*}{ Fase 3: } & f) & Jaguarão; \\
\hline & & g) & Arroio Grande. \\
\hline \multirow[t]{4}{*}{ Região 2: } & \multicolumn{3}{|l|}{ Serra do Sudeste: } \\
\hline & \multirow[t]{3}{*}{ Fase 4: } & h) & Piratini; \\
\hline & & i) & Encruzilhada do Sul; \\
\hline & & j) & Aceguá. \\
\hline \multirow[t]{12}{*}{ Região 3: } & \multicolumn{3}{|l|}{ Pampa: } \\
\hline & Fase 5: & k) & Bagé; \\
\hline & \multirow[t]{3}{*}{ Fase 6: } & l) & Santana do Livramento; \\
\hline & & m) & Rosário do Sul; \\
\hline & & n) & São Vicente do Sul; \\
\hline & \multirow[t]{3}{*}{ Fase 7: } & o) & Quaraí; \\
\hline & & p) & Alegrete; \\
\hline & & q) & São Francisco de Assis; \\
\hline & \multirow[t]{2}{*}{ Fase 8: } & r) & Barra do Quaraí; \\
\hline & & s) & Uruguaiana; \\
\hline & \multirow[t]{2}{*}{ Fase 9: } & t) & Itaqui; \\
\hline & & u) & São Borja. \\
\hline
\end{tabular}

5 Região Litoral - região de campos; planície, agricultura (arroz) e pecuária; Fronteiras: NO - Serra do Sudeste, O - Uruguai, SE - Oceano Atlântico, NE - Lagoa dos Patos. Região 2 - Serra do Sudeste: região de campos; serra; agricultura (milho e madeira) e pecuária; Fronteiras: NO - Pampa, SO - Uruguai, SE - Litoral, NE - Serra dos Tapes. Região 3 - Pampa Gaúcho: região de campos; planície; agricultura (arroz e soja) e pecuária; Fronteiras: NO - Argentina, SO - Uruguai, SE - Serra do Sudeste, NE - Planalto. 
O Banco de Dados Sociolinguísticos da Fronteira e da Campanha Sul-RioGrandense (BDS PAMPA) organizou-se levando em conta as características diatópicas que melhor representassem os objetivos inicialmente propostos, principalmente no que se refere à necessidade de os informantes serem moradores de regiões urbanas dos 21 municípios da fronteira sul do Brasil previamente selecionados. Para melhor compreensão da abrangência e da dimensão do projeto, a Figura 1 a seguir exemplifica as regiões e municípios que compõem o BDS PAMPA, seguindo o critério de proximidade geográfica por rodovia de acesso às comunidades de cada microrregião, já constituindo um princípio de divisão da região da fronteira.

Figura 1. Regiões e municípios alvos do BDS PAMPA

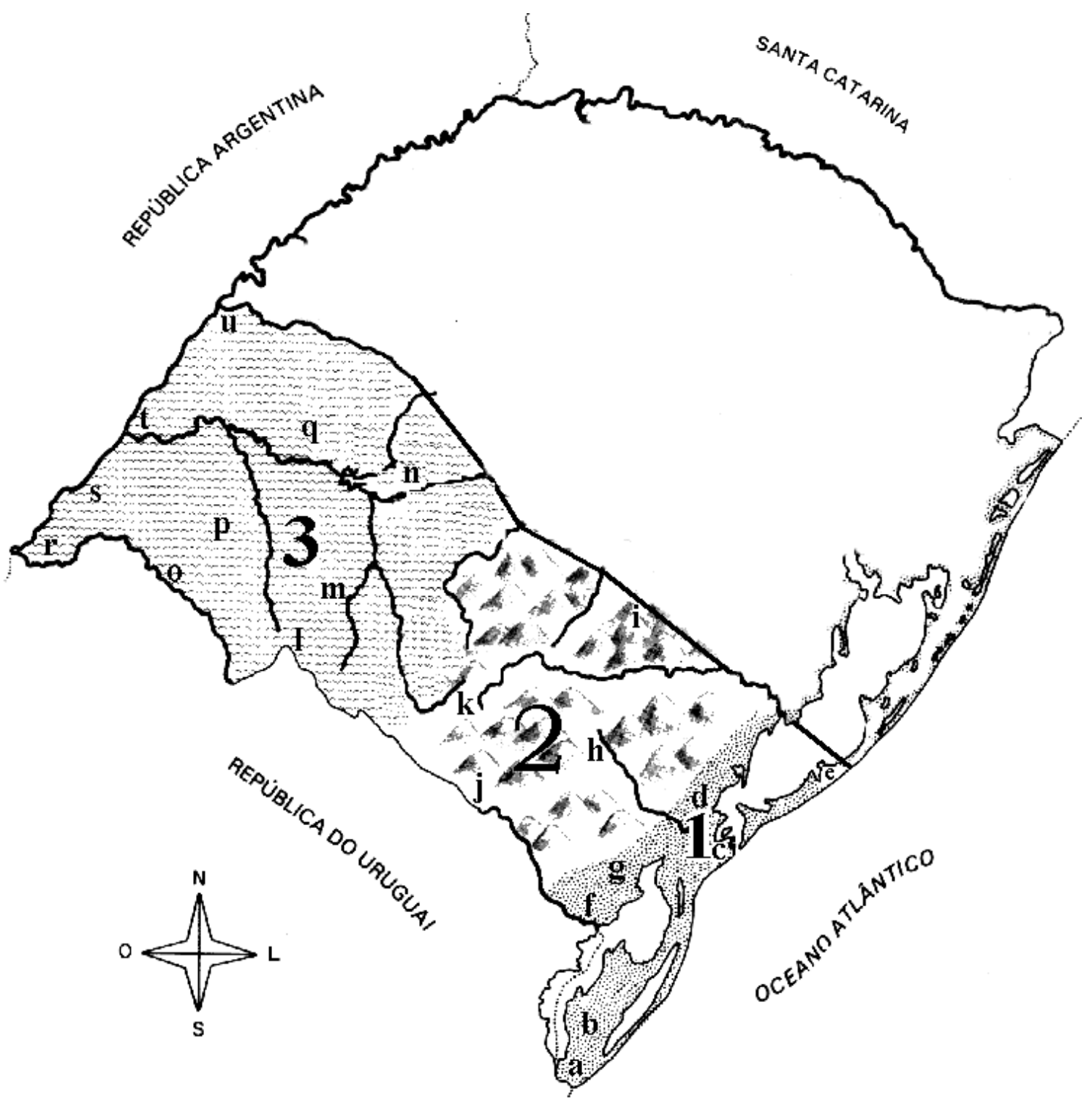


- Banco de dados sociolinguísticos da fronteira e da campanha sul-rio-grandense - BDS Pampa um percurso histórico

É importante salientar que, dos 21 municípios que compõem o BDS PAMPA, nem todos foram contemplados com a coleta dos dados dos 24 indivíduos e com o término das etapas metodológicas inicialmente propostas. Em 11 municípios ocorreram as coletas dos dados, com as devidas entrevistas gravadas, transcrições das falas, degravações e arquivamentos em computador e CD. As cidades incluídas no banco de dados foram da Região 1 - Litoral (Chuí, Santa Vitória do Palmar, Rio Grande, Pelotas, Tavares, Jaguarão e Arroio Grande), da Região 2 - Serra do Sudeste (Encruzilhada do Sul e Aceguá) e Região 3 - Pampa (Bagé e Santana do Livramento).

A metodologia de formação do banco de dados sociolinguísticos seguiu, para cada conjunto de dados coletados, as seguintes etapas operacionais: entrevista (obtenção dos dados sociolinguísticos e dos linguísticos in natura); catalogação da ficha sociolinguística; transcrição ortográfica dos dados linguísticos das cidades; transcrição fonética dos dados linguísticos; digitação e conferência dos dados linguísticos.

\section{A catalogação da ficha sociolinguística, as entrevistas, a digitação e a conferência dos dados linguísticos}

Os dados sociolinguísticos, bem como os dados cadastrais de cada informante, foram registrados em ficha especial, denominada "Questionário Prévio", criado especificamente para este fim, seguindo os pressupostos da Teoria da Variação (LABOV, 1972), a qual prevê a análise dos fenômenos linguísticos a partir do estudo de variáveis sociais.

No Questionário Prévio, foi possível verificar diferentes aspectos sociais relacionados aos informantes e às comunidades de fala investigadas. Além dos fatores sociolinguísticos clássicos estratificadores da amostra como faixa etária, sexo, escolaridade e localidade, também foram controlados outros aspectos importantes como classe social, renda, identidade e atitude linguística, sendo que, para zonas de contato com outras línguas, foram acrescentadas outras variáveis relativas ao grau de contato com outra língua e/ou com o PB. O Questionário Prévio encontra-se em anexo ao artigo e nele se pode constar a existência de múltiplas variáveis correlacionadas que são importantes para as análises variacionistas. Além disso, são encontradas perguntas onde há mudança de pessoas do discurso, ora com a utilização de "tu" ora com a utilização de "você", justamente para acentuar a interação e permitir que o entrevistado seja contemplado como partícipe natural do processo sociolinguístico de entrevista.

Os dados sociolinguísticos, registrados e codificados no Questionário Prévio, foram catalogados em arquivo índice, mediante digitação em ambiente computacional 
específico do sistema. Tal entrada de dados permitiu armazenar, consultar e processar diferentes variáveis sociolinguísticas. Foi possível recuperar, cruzar e submeter a processamento estatístico tais informações, bem como associá-las, sempre que pertinente, a variáveis de cunho linguístico.

Com relação às entrevistas, os dados linguísticos in natura, constituindo os depoimentos de cada informante, foram gravados em fita magnética tipo cassete. Para tal, foram adquiridos aparelhos portáteis de gravação de alta fidelidade. A duração média das entrevistas foi de cerca de 40 minutos, sendo que o mínimo era de 30 minutos e o máximo de 60 minutos.

Além disso, foi projetada uma planilha de transcrição e adotado um sistema de notações linguísticas, onde foi transcrita a fala mediante utilização do sistema ortográfico, combinado com um sistema especial de transcrição de conversação, a ser selecionado entre os disponíveis, bem como a apresentação de marcadores de tempo de 30 em 30 segundos na transcrição, como pode ser observado no fragmento de uma entrevista da cidade de Pelotas, apresentado a seguir.

Cabeçalho: D2 - (Masc. Esc1 - 16-20) BDS Pampa Região I (Litoral) - Pelotas

E: como é que foi? conta assim / como foi assim o teu atropelamento?

I: ah / desde o começo foi assim / quando eu estava atravessando o meio da rua / uma moto me atropelou né? / aí depois eu fui direto pro hospital e aí fui pra santa casa né? / eles iam me deixar 0200 com a perna curta né? / aí depois me levaram pro beneficência a / e / aí me operaram / botaram a tala / botaram meu pé pendurado assim num tipo de um / uma corda assim em cima do hospital vi que estava amarrada / aí depois me operaram / botaram gesso / aí daí daqui uns quatro meses me tiraram gesso / eu fiquei fazendo 0230 fisioterapia / aí depois eu fui $<$ melho $><$ merolhã $><$ merolhando $>$ e / aí de / aí depois eu $<$ merolhei $>$ mero $<$ merolhei $>$ e comecei a seguir a minha vida daí adiante /

Conforme pode ser observado no fragmento apresentado, foram efetuadas também observações linguísticas referentes a aspectos fonéticos e morfossintáticos das sequências registradas, sendo que, no caso de palavras não dicionarizadas ou incompletas, foram inseridos colchetes angulados. 
- Banco de dados sociolinguísticos da fronteira e da campanha sul-rio-grandense - BDS Pampa um percurso histórico

Quanto à digitação e conferência dos dados linguísticos, uma vez transcritos, os dados linguísticos foram digitados mediante editor de texto convencional ou ambiente específico, de acordo com uma estrutura de arquivo com quatro campos: identificação, apontando para o registro correspondente no arquivo de índice, transcrição ortográfica, transcrição fonética e campo reservado para notações morfossintáticas. Após a transcrição dos dados linguísticos, os mesmos passaram por revisão, a fim de verificar se as transcrições estavam adequadas às normas estabelecidas pelo projeto. A partir de sua digitação, os dados linguísticos tornam-se disponíveis para codificação e processamento. O BDS PAMPA obteve recurso para custeio, principalmente da FAPERGS, o que possibilitou a compra de material permanente e de consumo para o desenvolvimento da pesquisa, viagens e diárias. Com relação a bolsas de iniciação científica, os estudantes envolvidos no projeto receberam bolsas da FAPERGS, PIBIC-CNPq e também bolsas oriundas das próprias instituições envolvidas.

\section{Revisitando alguns trabalhos com fontes no BDS PAMPA}

O Quadro 2 sistematiza alguns trabalhos que merecem atenção especial como forma de trazer informações sobre a diversidade linguística trabalhada no corpus do BDS PAMPA, a partir de diferentes possibilidades de pesquisa e análise propostas pelos pesquisadores abaixo relacionados. 
Quadro 2. Pesquisas realizadas com o BDS PAMPA

\begin{tabular}{|c|c|c|}
\hline Fenômeno investigado & Cidade(s) pesquisada(s) & Autor/Ano \\
\hline $\begin{array}{l}\text { 1- Discurso reportado e } \\
\text { estrutura da narrativa }\end{array}$ & Pelotas & Amaral (2002) \\
\hline $\begin{array}{l}\text { 2- Gramaticalização de a gente } \\
\text { no PB }\end{array}$ & Jaguarão e Pelotas & Borges (2004) - tese \\
\hline 3- Análise de clíticos & $\begin{array}{l}\text { Chuí, Jaguarão e Pelotas } \\
\text { - Bagé } \\
\text { - Santana do Livramento } \\
\text { - Santana do Livramento } \\
\text { (BDS PAMPA), Santana do } \\
\text { Livramento e Porto Alegre } \\
\text { (VARSUL) }\end{array}$ & $\begin{array}{l}\text { Vandresen (2004) } \\
\text { Brisolara (2004a) - } \\
\text { dissertação } \\
\text { Brisolara (2006) } \\
\text { Brisolara (2008a) - tese }\end{array}$ \\
\hline 4- Palatalização de /t/ e /d/ & $\begin{array}{l}\text { Chuí } \\
\text { Chuí }\end{array}$ & $\begin{array}{l}\text { Brisolara (2003) } \\
\text { Dutra }(2007)\end{array}$ \\
\hline 5- Lateral pós-vocálica & $\begin{array}{l}\text { - Chuí e Santana do } \\
\text { Livramento } \\
\text { - Chuí, Santa Vitória do } \\
\text { Palmar, Pelotas, Rio Grande e } \\
\text { Santana do Livramento }\end{array}$ & $\begin{array}{l}\text { Espiga (2001) - tese } \\
\text { Espiga (2009) }\end{array}$ \\
\hline $\begin{array}{l}\text { 6- Futuro do presente no } \\
\text { português }\end{array}$ & Pelotas & Nunes (2003) - dissertação \\
\hline $\begin{array}{l}\text { 7- Alternância de códigos } \\
\text { português-espanhol }\end{array}$ & Chuí & $\begin{array}{l}\text { Ribeiro de Amaral (2008) } \\
\text { - tese }\end{array}$ \\
\hline 8- Concordância verbal & $\begin{array}{l}\text { Pelotas e Rio Grande } \\
\text { Chuí } \\
\text { Pelotas }\end{array}$ & $\begin{array}{l}\text { Brisolara e Vandresen } \\
(2000) \\
\text { Brisolara (2003) } \\
\text { Santos (2015) }\end{array}$ \\
\hline
\end{tabular}

Os trabalhos tratam de diferentes áreas dos estudos linguísticos como: tipo de discurso e estrutura narrativa (AMARAL, 2002), variação, mudança e gramaticalização (BORGES, 2004), colocação pronominal e prosodização de clíticos (VANDRESEN, 2004, BRISOLARA, 2004, 2006, 2008), palatalização das oclusivas dentais em comunidade fronteiriça: variação e mudança em progresso (BRISOLARA, 2003; DUTRA 2007), o contato do português com o espanhol e a produção da lateral pós-vocálica (ESPIGA, 2001, 2009), a variação entre a forma sintética e a perifrástica do futuro do presente do latim ao português (NUNES, 2003), bilinguismo, contato de línguas e codeswitching (RIBEIRO DO 
- Banco de dados sociolinguísticos da fronteira e da campanha sul-rio-grandense - BDS Pampa um percurso histórico

AMARAL, 2008), uso variável da concordância do pronome "tu" em região fronteiriça e não fronteiriça, relação entre concordância verbal de terceira pessoa do plural e classe social (SANTOS, 2015).

Os trabalhos elencados no Quadro 2 estão devidamente referendados na bibliografia aqui disponibilizada, demonstrando a diversidade de temas, propostas teóricas e metodológicas que foram pesquisadas e desenvolvidas a partir do BDS PAMPA.

\section{Convergindo pesquisas 20 anos depois: tempo aparente e tempo real}

Os trabalhos na área da sociolinguística têm demonstrado que os indivíduos modificam seus hábitos e comportamentos durante suas vidas, embora saibamos que as comunidades de fala mantêm padrões próprios identificadores das estratificações sociais pertencentes a determinada comunidade. Levando-se em consideração a importância e a abrangência do BDS PAMPA, seria importantíssimo para os estudos sociolinguísticos que a investigação fosse retomada após 20 anos da primeira coleta dos dados dos informantes participantes da pesquisa.

Esse desafio de revisitar as comunidades e regravar novos corpora está sendo planejado justamente para que seja possível identificar qual é a diferença em tempo real em torno de uma mesma pesquisa, para responder as seguintes questões: (a) houve mudança no que se refere ao uso das variáveis sociais e linguísticas encontradas em 1998 e em 2021; (b) há diferença e/ou predominância dos parâmetros sociais sobre os estruturais; (c) é possível verificar as distinções propostas por Labov (1994) em termos de estereótipos, marcadores ou indicadores relacionados às mudanças em tempo real, características sociolinguísticas atreladas às mudanças sociais, de estilo, nível de consciência social, origem e propagação das mudanças?

O BDS PAMPA, por suas características, poderá contribuir efetivamente para o entendimento da variação e das mudanças linguísticas, associando a outros importantes bancos de dados que se utilizaram das análises em tempo aparente e real como as pesquisas realizadas a partir dos bancos de dados NURC e VARSUL.

\section{BDS PAMPA: proposta metodológica para recontado e nova pesquisa}

Trabalhar com coleta de dados sociolinguísticos não é tarefa fácil. Bancos de dados representativos da fala de comunidades gaúchas, como o NURC, VARSUL, BDS PAMPA e VarX, necessitaram de muito trabalho para serem constituídos e para conseguirem atingir seus objetivos de coletar dados da fala de inúmeros informantes de diferentes 
comunidades gaúchas. Foram muitas horas, muitos dias e anos de trabalho, envolvendo diversos pesquisadores, bolsistas, investigadores, colaboradores e contatos com pessoas das mais variadas comunidades gaúchas. Essa diversidade de culturas e espaço físico, representadas por dimensões sociolinguísticas tão variadas, necessita um olhar atento do pesquisador para que os dados a serem coletados possam contemplar as múltiplas possibilidades de correlações possíveis entre os aspectos sociais e os aspectos linguísticos.

Além das variáveis sociais tradicionais como faixa etária, sexo, escolaridade, localidade, outros aspectos voltados para as relações entre os indivíduos e os grupos são de extrema importância para os estudos sociolinguísticos, com os estudos de redes sociais aplicadas à sociolinguística (GUMPERZ, 1976; LABOV, 1972, MILROY, 1980), trabalhos que tratam de padrões de variações de múltiplas variáveis (OUSHIRI; GUY, 2015), processos de acomodação dialetal (GILES; COUPLAND, 1991), classe social (GUY, 1987; BOURDIEU, 1991; CHAMBERS, 1995), atitudes e identidade (HORA, 2015; AMARAL, 2016).

Trata-se, portanto, de uma proposta que merecerá um novo olhar, revisitando-se a teoria e as pesquisas sociolinguísticas e preparando-se para este novo momento tão dinâmico e multifacetado relacionado aos processos de mudança e variação linguística. Eckert (2012), nesse sentido, menciona essa "terceira onda da sociolinguística" como forma de compreender melhor a dinâmica social e linguística dos múltiplos fenômenos sociolinguísticos variacionistas. Ou seja, revalorizar os significados sociais da variação e suas implicações com os contextos de usos da língua. Como afirma Mendes (2017, p. 121), "o modo como nos concebemos no mundo importa para o modo como falamos". Nesse aspecto, metodologicamente, duas propostas merecerão atenção especial: (1) recontato com os informantes do banco de dados do BDS PAMPA da década de 1990 das cidades de Pelotas, Rio Grande, Santa Vitória do Palmar e Jaguarão; (2) nova coleta de dados, nessas mesmas localidades, conforme estratificação social da coleta realizada na década de 1990, com novos informantes com as mesmas faixas etárias, mesmo sexo e mesma escolaridade dos informantes entrevistados e que tiveram os dados de fala coletados há mais de 20 anos. Para tanto, a Universidade Federal de Rio Grande (FURG) integrará a parceria interinstitucional, somando esforços para que possamos efetivar da melhor maneira possível este "novo" projeto tão importante de descrição do português do Brasil da Fronteira e da Campanha Sul-Rio-Grandense. O trabalho de recontato é importante, haja vista que as práticas culturais e sociais são dinâmicas. Faraco (2019, p. 16), nesse aspecto, afirma que "as sociedades têm história. Elas são, por consequência, também heterogêneas, contraditórias, simultaneamente integradas, fragmentadas em constante devir". 
- Banco de dados sociolinguísticos da fronteira e da campanha sul-rio-grandense - BDS Pampa um percurso histórico

Outro ponto importante que deverá merecer atenção especial diz respeito aos dados presentes na catalogação da ficha sociolinguística dos informantes. Uma nova ficha especial deverá ser organizada para registrar as informações sociolinguísticas de cada informante, além de seus dados cadastrais, levando-se em conta os novos aspectos sociolinguísticos que serão observados. Além dos dados pessoais como profissão, escolaridade, outros dados importantes serão contemplados como orientação de gênero, atitudes, papéis sociais, identidade, redes sociais. Esses aspectos, representativos da realidade social atual, servirão para que se possa conhecer melhor a realidade social de cada um dos informantes.

\section{Referências}

AMARAL, L. I. C. Centeno A importância de variáveis estilístico-discursivas para as análises de fenômenos lingüísticos variáveis. In: VANDRESEN, P. (ed.). Variação e mudança no português falado da região sul. Pelotas: EDUCAT, 2002. p. 47-68.

AMARAL, M. P. do. Crenças e atitudes linguísticas. In: BRISOLARA, L. B.; TAGLIANI, D. C. Estudos da linguagem: diferentes olhares. Campinas: Pontes Editores, 2016.

BOURDIEU, P. Language and symbolic power. Cambridge: Harvard University Press, 1991.

BORGES, P. R. S. A gramaticalização de a gente no português brasileiro: análise histórico-social-linguística da fala das comunidades gaúchas de Jaguarão e Pelotas. 2004. Tese (Doutorado em Letras) - Instituto de Letras, Universidade Federal do Rio Grande do Sul, Porto Alegre, 2004.

BRISOLARA, L. B.; VANDRESEN, P. A concordância variável do pronome tu em Pelotas e Rio Grande - RS. In: $4^{\circ}$ Encontro do CELSUL, 2000, Curitiba - PR, 2000.

BRISOLARA, L. B.; VANDRESEN, P.; MATZENAUER, C. L. O prestígio lingüístico como limitador da autonomia. In: II Fórum Internacional de Ensino de Línguas Estrangeiras Anais do FILE II. Pelotas, 2002.

BRISOLARA, L. B."Tu foste" ou "tu foi"? Um estudo sobre a concordância com o pronome "tu". In: III Seminário Nacional de Linguagem e Ensino - SENALE. v. 2. Pelotas: TELA, 2003. 
BRISOLARA, L. B. A prosodização dos clíticos pronominais no sul do Brasil: uma análise variacionista com base na elevação da vogal átona /e/. 2004. Dissertação (Mestrado em Letras) - Universidade Católica de Pelotas, Pelotas, 2004a.

BRISOLARA, L. B. O comportamento da vogal átona /e/ de clíticos em cidade de fronteira com o Uruguai. In: II Encontro Nacional de Ciências da Linguagem Aplicadas ao Ensino (ECLAE) - Anais. João Pessoa: Idéia, 2004b.

BRISOLARA, L. B. Cliticização pronominal no Sul do Brasil: uma abordagem à luz da fonologia prosódica In: VANDRESEN, P. Variação, mudança e contato lingüístico no português da Região Sul. Pelotas: EDUCAT, 2006. p. 169-183.

BRISOLARA, L. B. Os clíticos pronominais no português brasileiro e sua prosodização. 2008. Tese (Doutorado em Letras) - Pontifícia Universidade Católica, Rio Grande do Sul, Porto Alegre, 2008a.

BRISOLARA, L. B. A elevação das vogais átonas /e/ e /o/ de clíticos pronominais na comunidade de Santana do Livramento. In: ESPIGA, J.; ELIZAINCÍN, A. Español y portugués: um (velho) novo mundo de fronteiras e contatos. Pelotas: EDUCAT, 2008b. p. 107-127.

BRISOLARA, L. B; MATZENAUER, C. L. B.; VANDRESEN, P. A palatalização das plosivas coronais como inserção de traços. In: $5^{\circ}$ Encontro do CELSUL, 2003, Curitiba-PR. Anais do $5^{\circ}$ Encontro do CELSUL. Curitiba, 2003.

BRISOLARA, L. B.; MATZENAUER, C. L. B. O comportamento da vogal átona /E/ de clíticos pronominais e os processos de sândi. In: $6^{\circ}$ Círculo de Estudos Lingüísticos do Sul, 2004, Florianópolis. Anais do $6^{0}$ Círculo de Estudos Lingüísticos do Sul, 2004.

CHAMBERS, J. K. Sociolinguistic theory: Linguistic variation and its social significance. Cambridge: Blackwell, 1995.

DUTRA, E. de O. A palatalização das oclusivas dentais /t/ e /d/ no município do Chuí. 2007. Dissertação (Mestrado em Letras) - Pontifícia Universidade Católica do Rio Grande do Sul, Porto Alegre, 2007.

ECKERT, P. Three waves of variation study: the emergence of meaning in the study of sociolinguistic variation. Annual Review of Anthropology. Palo Alto. 41, p. 87-100, 2012. 
- Banco de dados sociolinguísticos da fronteira e da campanha sul-rio-grandense - BDS Pampa um percurso histórico

ESPIGA, J. W. da R. O Português dos Campos Neutrais. Um estudo sociolingüístico da lateral pos-vocálica nos dialetos fronteiriços de Chuí e Santa Vitória do Palmar. 2001. Tese (Doutorado em Letras) - Pontifícia Universidade Católica do Rio Grande do Sul, Porto Alegre, 2001.

ESPIGA, J. W. da R. O contato com o espanhol na sincronia: análises contrastivas de dialetos do português fronteiriço. 2009. Disponível em: http://www.leffa.pro.br/tela4/ Textos/Textos/Anais/SENALE_IV/IV_SENALE/Jorge_Espiga.htm. Acesso em: 21 out. 2017.

FARACO, C. A. História do português. São Paulo: Parábola, 2019.

FINATTO, M. J. B. Corpus-amostra português do século XVIII: textos antigos de medicina em atividades de ensino e pesquisa. Domínios da Lingu@gem, Uberlândia, v. 12, n. 1, jan./mar. 2018.

GILES, H.; COUPLAND, N. Language: contexts and consequences. Pacific Grove (Ca): Brooks, Cole, 1991.

GUMPERZ, J. J. The sociolinguistic significance of conversational code-switching. Working Paper 46. Berkeley: Language Behavior Research Laboratory, 1976.

GUY, G. R. Language and social class. Linguistics: The Cambridge survey, v. 4, p. 37-63, 1987.

HALL, S. Identidade cultural na pós-modernidade. Rio de Janeiro: DP\&A, 2002.

HORA, D. da; MARTINS, M. A.; SAVEDRA, M. M. G. Atitude do ouvinte versus estilo e variação do falante. In: HORA, D.; GUIMARÃES, M. M. S.; MARTINS, M. A. (org.). Identidade social e contato linguístico no português brasileiro. v. 1. Rio de Janeiro: Eduerj, 2015. p. 73-100.

LABOV, W. Language in the Inner City. Filadélfia: Pennsylvania University Press, 1972.

LABOV, W. Principles of Linguistic Change. v. 1. Oxford: Blackwell Publishers, 1994.

MENDES, R. B. A terceira onda da Sociolinguística. In: FIORIN, J. L. (org.). Novos caminhos da linguística. São Paulo: Contexto, 2017. 
MILROY, L. Language and Social Networks. Oxford: Blackwell, 1980.

NUNES, R. Evolução cíclica do futuro do presente do latim ao português. 2003.

Dissertação (Mestrado em Letras) - Universidade Católica de Pelotas, Pelotas, 2003.

OUSHIRO, L.; GUY, G. R. The efect of salience on covariation in Brazilian Portuguese.

Penn Working Papers in Linguistics, v. 21, p. 157-166, 2015.

RASO, T. Aspectos sociais e pragmáticos da Linguística de Corpora. In: MOLLICA, M. C; FERRAREZI JUNIOR, C. Sociolinguística, sociolinguísticas: uma introdução. São Paulo: Contexto, 2016.

RIBEIRO DE AMARAL, T. Una comunidad de habla, dos comunidades de lengua: La alternancia de códigos como signo de identidad en la frontera Brasileño-Uruguaya. 2008. Tese (Doutorado em Língua Espanhola e Linguística Geral) - Universidad Autónoma de Madrid, Madri, 2008.

SANTOS, G. R. dos. A concordância verbal variável em Pelotas: um estudo sociolinguístico por classe social. Saarbrücken, Deutschland: Novas Edições Acadêmicas, 2015.

VANDRESEN, P. Os clíticos no português da fronteira gaúcha: Chuí, Jaguarão e Pelotas. In: Anais da XX Jornada do GELNE - João Pessoa (PB). 2004. Disponível em: http:/ / www. gelne.com.br/arquivos/anais/gelne-2004/PDF/Paulino\%20Vandresen.pdf. Acesso em: 21 out. 2017. 
- Banco de dados sociolinguísticos da fronteira e da campanha sul-rio-grandense - BDS Pampa um percurso histórico

\section{Anexo 1}

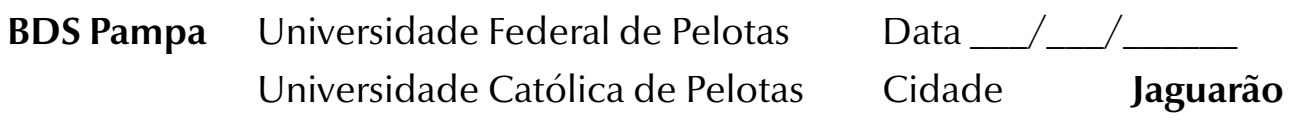

Local da coleta (rua, bairro)

\section{Questionário Prévio}

\begin{tabular}{|c|c|c|c|c|}
\hline \multicolumn{5}{|c|}{ Nome: } \\
\hline Sexo: & \multicolumn{2}{|l|}{ Ano de nascimento: } & \multicolumn{2}{|c|}{ Bairro em que mora: } \\
\hline \multicolumn{3}{|c|}{ Profissão: } & \multicolumn{2}{|l|}{ Ocupação: } \\
\hline \multicolumn{3}{|c|}{ Estás satisfeito com o teu trabalho: $\square$ Sim $\square$ Não } & \multicolumn{2}{|l|}{ or quê? } \\
\hline \multicolumn{3}{|c|}{ Gostaria de exercer outra profissão? $\square$ Sim $\square$ Não } & \multicolumn{2}{|c|}{ Qual? } \\
\hline \multicolumn{5}{|c|}{ Que profissão não gostarias de exercer? } \\
\hline \multicolumn{2}{|c|}{ Participa de Associação de Classe (líder): } & \multicolumn{2}{|l|}{ Qual? } & Função: \\
\hline \multicolumn{2}{|c|}{ Escolaridade? } & \multicolumn{2}{|c|}{ Quanto tempo esteve na escola? } & _ anos \\
\hline \multicolumn{2}{|c|}{ Escolaridade dos pais? } & \multicolumn{3}{|c|}{ Escolaridade dos filhos? } \\
\hline \multicolumn{2}{|c|}{ Gostas de ler? $\square$ Sim $\square$ Não } & \multicolumn{3}{|c|}{ O que lê? (frequência) } \\
\hline \multicolumn{3}{|c|}{ Gostas de morar aqui em Jaguarão? $\square$ Sim $\square$ Não } & \multicolumn{2}{|c|}{$\begin{array}{l}\text { Há quanto tempo moras nesse } \\
\text { bairro? }\end{array}$} \\
\hline \multicolumn{3}{|c|}{ Gostas do bairro onde moras? $\square$ Sim $\square$ Não } & \multicolumn{2}{|c|}{$\begin{array}{l}\text { As pessoas aqui são legais? } \\
\square \text { Sim } \square \text { Não }\end{array}$} \\
\hline \multicolumn{3}{|c|}{ Teus amigos moram neste bairro? $\square$ Sim $\square$ Não } & \multicolumn{2}{|c|}{ Em que outra cidade gostarias de morar? } \\
\hline \multicolumn{5}{|c|}{ Conheces alguém aqui deste bairro que sabe contar histórias? $\square$ Sim $\square$ Não } \\
\hline \multicolumn{5}{|c|}{ Podes me dar o nome ou endereço (ou telefone) dessa pessoa? } \\
\hline \multicolumn{5}{|l|}{ End.: } \\
\hline \multirow{2}{*}{\multicolumn{2}{|c|}{ Na tua opinião, como é a maioria dos uruguaios? }} & \multicolumn{3}{|c|}{$\square$ avaliação positiva (+) } \\
\hline & & \multicolumn{3}{|c|}{$\square$ avaliação negativa (-) } \\
\hline
\end{tabular}




\begin{tabular}{|c|c|}
\hline \multicolumn{2}{|c|}{ Como eles são no trabalho? $\square(+) \quad \square(-)$ Como eles são nas festas? $\square(+) \quad \square(-)$} \\
\hline \multicolumn{2}{|c|}{ Pensaste em algum uruguaio(a) em especial? $\square$ sim $\square$ não (se sim, sexo e idade): } \\
\hline Tens parentes uruguaios? (grau) $\quad \square$ sim $\square$ não & Tu compreendes a fala deles? $\square \operatorname{sim} \quad \square$ não \\
\hline \multicolumn{2}{|c|}{ Eles falam o que mesmo (como é o nome)? } \\
\hline \multicolumn{2}{|c|}{ Fazes compras aqui em Jaguarão? $\square$ Sim $\square$ Não Se não: em que cidade compras? } \\
\hline Onde compras alimentos? & Em que loja compras roupas? \\
\hline \multirow[t]{2}{*}{ As roupas são caras nessa loja? $\square$ Sim $\square$ Não } & \multirow{2}{*}{$\begin{array}{l}\text { Onde fica essa loja, é aqui no bairro? } \\
\square \operatorname{Sim} \square \text { Não }\end{array}$} \\
\hline & \\
\hline A casa em que moras é: $\square$ própria $\square$ alugada & Tens TV colorida? $\square$ Sim $\square$ Não \\
\hline Tem automóvel (modelo, ano)? & Tens geladeira? $\square$ Sim $\square$ Não \\
\hline \multirow[t]{2}{*}{ Tens telefone? (fixo, celular) $\square$ Sim $\square$ Não } & \multirow{2}{*}{$\begin{array}{l}\text { Tens rádio? } \square \text { Sim } \square \text { Não } \\
\text { Tens empregada? } \square \text { Sim } \square \text { Não }\end{array}$} \\
\hline & \\
\hline Qual é a renda da família? & Jaguarão está melhor ou pior do que antes? \\
\hline Atividade social ou de lazer preferida: & Locais que frequenta (clube, boate...) \\
\hline \multicolumn{2}{|l|}{ Que tipo de música gosta de ouvir com mais frequência? } \\
\hline \multicolumn{2}{|l|}{$\square$ pagode $\square$ rock $\square$ clássica $\square$ gauchesca } \\
\hline \multicolumn{2}{|l|}{ Qual cantor (ou músico) que mais preferes? } \\
\hline Entrevistador: & Instituição: \\
\hline Falante do dialeto $\square$ Popular $\square$ Culto & Fala $\square$ bastante $\square$ pouco \\
\hline \multicolumn{2}{|l|}{ Obs.: } \\
\hline
\end{tabular}


- Banco de dados sociolinguísticos da fronteira e da campanha sul-rio-grandense - BDS Pampa um percurso histórico

COMO CITAR ESTE ARTIGO: BORGES, Paulo Ricardo Silveira; BRISOLARA, Luciene Bassols. Banco de dados sociolinguísticos da fronteira e da campanha sul-rio-grandense - BDS Pampa - um percurso histórico. Revista do GEL, v. 17, n. 2, p. 82-101, 2020. Disponível em: https://revistadogel.gel.org.br/

DOI: http://dx.doi.org/10.21165/gel.v17i2.2107

Submetido em: 23/03/2018 | Aceito em: 08/07/2020. 